\title{
JUSTIÇA ADMINISTRATIVA NO BRASIL DO SEGUNDO REINADO (1842-1889)
}

\author{
Lydia Magalhães Nunes Garner \\ Professora - Departamento de História - Southwest Texas State University
}

\section{Resumo}

Propõe-se no presente artigo discutir o exercício de Justiça Administrativa na Seção do Império do Conselho de Estado no Segundo Reinado.

\section{Abstract}

The purpose of this article is to discuss the practice of Administrative Justice in the Section of Empire of the Council of State in the Second Reign.

\section{Pallavras-Chave}

Seção do Império • Conselho de Estado • Justiça Administrativa • Segundo Reinado $\bullet$ Contencioso Administrativo

\section{Keywords}

Section of Empire - Council of State - Administrative Justice • Second Reign $\bullet$ Litigious Administrative 


\section{Introdução}

$\mathbf{U}$ ma das funções menos conhecidas do Conselho de Estado do Segundo Reinado é a de corte suprema de apelação de justiça administrativa, função que é praticamente desconhecida na nossa história jurídica e administrativa em parte devido à falta de estudos de pesquisa sobre a implantação e desenvolvimento da justiça administrativa durante o Império. Esta escassez tem levado alguns estudiosos a opinarem de modo diverso sobre a sua existência, como Temístocles Brandão Cavalcanti, para quem a "jurisdição administrativa praticamente não tinha existência" na Monarquia (Cavalcanti 1964: 508) ou Caio Tácito, que descreve o Conselho de Estado como um orgão "sem atribuições jurisdicionais” (Tácito 1978: 64) e Alfredo Rocha (1914), que é de opinião que este "não chegou nunca a ter entre nós organização metódica e regular". Por outro lado, Dalmo de Abreu Dallari (1970: 33) lamenta a falta de estudos sobre o Conselho de Estado e José Cretella Junior (1972: 45) afirma que é "inegável a existência do contencioso administrativo na época imperial". Uma análise mais a fundo desta função demonstra que o Conselho de Estado não somente teve atribuições jurisdicionais mas também jurisdição administrativa metódica e regular, e consequentemente, teve uma ação direta e contínua na estruturação do Estado nacional como instituição auxiliar do poder Executivo e como tribunal de apelação de justiça administrativa.

Oficialmente o Conselho de Estado tinha duas funções consultivas, uma política e outra administrativa. O Conselho de Estado Pleno era o conselho político (composto de doze membros vitalícios) no qual os conselheiros aconselhavam o imperador nos assuntos pertinentes ao poder Moderador e assuntos de Estado; o conselho administrativo era o mesmo Conselho Pleno e seus membros, dividido em quatro Seções nas quais os conselheiros aconselhavam os ministros em assuntos administrativos. Esta função consultiva foi ligeiramente mencionada na Lei 234 (Nov. 23, 1841) que reinstituiu o Conselho de Estado, e sucintamente definida no Regulamento 123 (Fev. 5, 1842) que lhe deu regimento provisório, o qual incumbiu cada Seção de examinar todas as leis provinciais "e todos os negócios de que a encarregar o seu 
presidente," o que significava aconselhar os respectivos ministros. Ao aconselhar os ministros "em todos os negócios" os conselheiros sugeriam medidas em todas as áreas sob a jurisdição dos respectivos ministérios, tais como propor projetos de lei e de regulamentos. Ao examinar anualmente as leis provinciais para determinar se a Constituição e as leis gerais estavam sendo obedecidas os conselheiros tinham uma função de supervisão. Mas ao dar organização ao Conselho de Estado, o Regulamento 124 também introduziu o Capítulo 3 intitulado "Dos Objetos Contenciosos," no qual foi determinado em 27 artigos quando e como justiça administrativa deveria ser exercida no Brasil (Arquivo do Museu Imperial, Maço 23, doc. 843) ${ }^{1}$. E com a introdução da justiça administrativa sob a jurisdição do Executivo os conselheiros ganharam uma função judiciária.

A Constituição de 1824 deu ao poder Executivo a prerrogativa de redigir projetos de lei apresentados ao Legislativo e também a de redigir os regulamentos uma vez que as leis houvessem sido aprovadas, o que permitia que projetos de lei fossem redigidos em termos gerais para facilitar a aprovação e que o verdadeiro espírito da lei fosse somente revelado no regulamento. Assim sendo, as atribuições jurisdicionais do Conselho de Estado estavam inseridas não na lei que o reinstituiu, mas no regulamento que lhe deu organização, fato que deve ter contribuído para a percepção errônea que continua a persistir nos dias atuais de que o Conselho nunca as possuiu. Fator notável neste Regulamento é que, apesar de ter sido criado em caráter provisório até que pudesse ser aperfeiçoado pelo que ditasse a experiência, o mesmo continuou em efeito até o fim da monarquia sem nunca ter sido modificado. A complementaridade de suas funções e a vitaliciedade dos conselheiros indicam a preocupação no período com a continuidade administrativa, dois fatores essenciais para se examinar os trabalhos do Conselho de Estado. Das quatro Seções do Conselho de Estado, Justiça e Negócios Exteriores, Marinha e Guerra, Fazenda, e Império somente esta última foi analisada em todas as suas funções, uma das quais era a de

\footnotetext{
${ }^{1}$ A organização do Conselho de Estado em 1842 foi moldada pelo Conseil d'État criado pela Constituição Francesa do Ano VIII (1799) e adaptada às condições nacionais.
} 
corte de apelação para assuntos contenciosos nas áreas sob a jurisdição dos Ministérios do Império e da Agricultura (Garner 1987). A área de jurisdição da Seção do Império era imensa se considerarmos as áreas sob a jurisdição destes dois ministérios (Apêndice).

\section{Introdução da Justiça Administrativa}

A introdução da justiça administrativa no Brasil em 1842 não era nem uma novidade nem incompatível com o passado histórico do país, se observarmos que uma forma de justiça administrativa havia sido exercida no período colonial e abolida na primeira década da Independência.

No Brasil colonial, litígios administrativos eram processados através de apelos e reclamações dirigidas aos soberanos Portugueses que podiam anular decisões judiciais. O Tesouro Público era a única área do governo colonial que tinha um foro especial para resolver assuntos litigiosos, o qual era o Conselho da Fazenda, cuja decisão podia ser apelada ao soberano em todos os casos de impostos e propriedade da Coroa. Esta mesma organização continuou no Brasil após a Independência sob a jurisdição do Ministério da Fazenda, fazendo deste Ministério o único com experiência na área de justiça administrativa contenciosa. Os outros Ministérios não tiveram a mesma oportunidade. Durante o reinado de Pedro I várias leis foram aprovadas eliminando os últimos vestígios herdados da administração colonial com a eliminação de repartições que tinham o poder de dispensar justiça administrativa, e transferindo a jurisdição para o poder Judicial. O processo de descentralização da Regência eliminou os últimos vestígios do sistema dual de justiça (Souza 1960: 92 94; Fleiuss 1922: 221-222; Cretella Junior s.d.: 94-112).

Com a organização do Tesouro Público Nacional em 1831, o Conselho do Tesouro foi abolido e as suas funções em matéria litigiosa foram transferidas para os juízes territoriais com apelos para a Relação, e as de concessão de favores para o Tribunal do Tesouro. Assim, o Executivo manteve o direito de dispensar favores, mas perdeu o de exercer justiça administrativa (Souza 1960: 95). Mas a divisão da jurisdição administrativa entre o Executivo e o Judiciário tornou-se problemática 
para o Tesouro Público por falta de coordenação, cada poder agindo independentemente sem tentar atingir consenso. A experiência certamente não passou despercebida aos políticos do período, fato que deve ter contribuído para a institucionalização da justiça administrativa sob o Executivo em 1842. Esta mudança já vinha de 1841, quando toda a jurisdição administrativa sobre o Tesouro foi dada ao Ministro da Fazenda e à Corte do Tesouro sobre a qual ele presidia, pondo sob a sua jurisdição ambas as áreas administrativas, a concessão de favores e a resolução de assuntos litigiosos, um retorno ao modelo colonial. Assim, quando o Regulamento 124 institucionalizou a justiça administrativa e a colocou sob a égide do Executivo, o Ministério da Fazenda já possuía esta prerrogativa, mas sendo o único Ministério que tradicionalmente tinha experiência com a justiça administrativa e tinha a sua própria corte de apelação.

Consequentemente, quando a justiça administrativa foi reinstituída, o sistema não era desconhecido no Brasil, pois tinha sobrevivido no Ministério da Fazenda. Esta é a razão pela qual justiça administrativa é sempre associada com este Ministério, deixando a impressão que não existiu em nenhum dos outros ministérios durante o reinado de Pedro II. Mas a inovação introduzida pelo Regulamento 123, em 1842, foi a de que a justiça administrativa foi institucionalizada como mais uma das prerrogativas do poder Executivo, e numa escala sem precedente histórico. Desde então, todos os outros Ministérios ganharam a prerrogativa de decidir em matérias litigiosas administrativas em todas as áreas sob a suas jurisdições através das respectivas Seções do Conselho de Estado.

\section{A Questão Constitucional}

A introdução da justiça administrativa na forma do Regulamento 123 levantou um problema constitucional. Para que a justiça administrativa pudesse ser exercida pelo Executivo era necessário um sistema dual de justiça, e separação completa de poderes entre o Executivo e o Judiciário. Neste sistema, a função do Judiciário era a de aplicar a lei civil e criminal, e a função do Executivo, além de governar e aplicar as leis políticas e administrativas, era também a de dispensar justiça administrativa. A Constituição de 1824, entretanto, não criou um sistema dual de justiça. Pelo con- 
trário, criou um poder Judicial independente e unitário. É bem verdade que a justiça administrativa não foi mencionada na Constituição, mas inerente ao poder independente do Judiciário estava implícito o exercício de todas as áreas de justiça, inclusive aquela de justiça administrativa (Constituição de 1824, Arts. 151, 164).

Pode ser afirmado então que o exercício da justiça administrativa pelo Executivo era inconstitucional? A resposta dependia da interpretação dada à Constituição no período. A Carta estipulou quatro poderes: Moderador, Legislativo, Executivo, Judiciário. O poder Moderador estava acima dos outros três, e consequentemente, o conceito de balança entre estes poderes, como na constituição dos Estados Unidos, não existia. $\mathrm{O}$ conceito que prevaleceu foi o de separação de poderes com reconciliação ao nível do poder Moderador. Assim, a Constituição de 1824 estipulava separação de poderes e sistema judicial unitário. Mas esta interpretação aparentemente não era tão clara durante o Segundo Reinado. A controvérsia sobre o direito do Executivo de exercer a justiça administrativa era sobrepujada somente pela controvérsia sobre a natureza do poder Moderador, e os argumentos a favor ou contra dependiam da interpretação dada à Constituição. Por exemplo, um editorial num jornal de São Paulo mantinha que na Constituição "não havia um simples artigo dando ao Executivo tal prerrogativa," enquanto que outro periódico mantinha que a prerrogativa foi criada pela Constituição" (A Província de São Paulo, Mar. 5, 1875; Diário de São Paulo, Mar. 3, 1875).

Assim, uma interpretação era baseada no sistema judicial unitário criado pela Constituição que considerava o exercício da justiça administrativa pelo Executivo inconstitucional, enquanto que a outra, era baseada no sistema de separação de poderes da mesma Constituição que criou poderes independentes entre si, o que não impedia o exercício da justiça administrativa (Souza 1960: 32-33; Lyra 1979: $173)^{2}$. Consequentemente, o ponto de contenção não era o estabelecimento de justiça

${ }^{2}$ A Revista do Instituto Histórico e Geográfico Brasileiro, 1914, oferece um sumário destas duas interpretações. 
administrativa, mas sim o fato de que foi posta sob a jurisdição do poder Executivo e não do Judicial. Parte desta contenção estava ligada à ideologia política dos dois partidos, o Liberal criticando e o Conservador endossando, parte ligada ao espírito da época de desconfiança do sistema judicial e de juízes em geral desde os dias da Revolução Francesa, e a influência do modelo administrativo francês que em 1840 incluía um Conselho de Estado com funções consultivas e judiciárias que coexistia com o governo de gabinete (Garner 2002).

Entre os problemas essenciais do período em que Pedro II subiu ao trono estavam os de restaurar a lei e a ordem e de organizar a estrutura administrativa, política, e judicial do Brasil, e para este fim, além do poder de planejar e supervisionar, era necessário também o poder judicial para julgar disputas resultantes do processo administrativo. Para os Conservadores, a implementação e consolidação de decisões do poder Executivo requeria que este poder, e não o Judicial, tivesse a autoridade final em assuntos sob a sua jurisdição. Do contrário, haveria o risco do Judiciário interferir nos atos do Executivo. Este ponto era crucial, e podia ser resolvido somente com a institucionalização da justiça administrativa sob a égide do Executivo. O Visconde de Uruguai, o mais enérgico promotor e o maior teórico da sua aplicação no Brasil, emprestou as palavras do jurista francês, Laferrière, para definir justiça administrativa como a "ciência das ações e da competência do poder Executivo, das administrações gerais e locais, e dos Conselhos Administrativos, em suas relações com os interêsses ou direitos dos administrados, ou com o interêsse geral do Estado"(Souza 1960: 19).

De acordo com Uruguai, o Executivo possuía duas áreas distintas de autoridade: uma era a constitucional, aquela de autoridade política e governamental compartilhada com o Legislativo que aplicava as leis diretamente e emitia regulamentos e medidas gerais. Esta era a autoridade que colocava o interesse da sociedade acima do interesse individual, enfim, a autoridade que governava e que era exercida pelos ministros e o chefe do poder Executivo. A segunda era a autoridade administrativa, subordinada ao poder político e pertencente ao Executivo. Esta autoridade era exercida, ou diretamente pelos ministros e chefe do executivo, ou indiretamente pelos 
seus agentes através do Império “dando ao serviço público um caráter em harmonia com a visão do Executivo." De acordo com Uruguai, autoridade administrativa estava sempre subordinada à autoridade política, ou, em suas palavras, "o poder político é a cabeça; a administração é o braço" (Souza 1960: 28).

Pertinente à autoridade administrativa, todavia, existiam duas áreas distintas: uma era a de administração graciosa, a prerrogativa constitucional do Executivo de conceder favores e concessões nas esferas sob a sua jurisdição e competência. Exemplos desta autoridade eram as concessões de privilégios e a seleção de propostas para a construção de obras públicas de acordo com a autoridade delegada pelo poder Legislativo. Desde que estas concessões eram de privilégio do Executivo, elas não interferiam ou violavam os direitos adquiridos de outros. $\mathrm{O}$ único dano à outras partes interessadas era o de não terem sido contempladas com a concessão. Por exemplo, se várias propostas eram submetidas para a construção de um projeto do governo, o Executivo tinha o poder discricionário de selecionar a proposta que mais beneficiasse o governo. O concessionário então tinha o direito de construir a obra, um direito que não podia ser revogado a não ser em caso de circunstâncias especiais. Das propostas não selecionadas, os interessados se nada tinham ganho, tampouco nada tinham perdido a não ser o interesse próprio. Inerente neste poder discricionário estava aquele do Executivo de reconsiderar as suas próprias ações. Nos casos do administrativo gracioso o apelo era feito através de representação das partes que julgavam seus interesses feridos por atos do governo, em cujos casos o governo tinha o poder discricionário de remediar a situação se julgasse que uma injustiça tinha sido cometida ou que fosse no interesse público. Mas o governo não era obrigado a tomar nenhuma medida (Souza 1960: 57-58).

A outra área pertinente à autoridade administrativa era a do chamado administrativo contencioso, que tinha o poder de resolver disputas contenciosas. Para que esta autoridade fosse invocada era necessário que um apelo judicial desse entrada contra uma ação do Executivo que tivesse ocasionado a perda de um direito adquirido. Ainda de acordo com Uruguai, uma vez que o Executivo concedesse um privilégio ou concessão, esta se tornava propriedade do recipiente. Qualquer violação ou revocação 
dos termos da concessão era uma violação de um direito adquirido e dava direito a um apelo judicial. Por exemplo, se o Executivo concedesse um privilégio numa área na qual uma concessão já houvesse sido feita, o primeiro contemplado tinha o direito de entrar com um apelo. Consequentemente, o contencioso administrativo se ocupava do específico, ou do indivíduo, não do que era geral, ou da sociedade. E, enquanto que ao conceder privilégios e concessões de natureza graciosa o Executivo tinha a prerrogativa de reconsiderar e corrigir suas ações, o mesmo não ocorria no caso do contencioso, pois o que era contestado era um direito adquirido que obrigava o governo a reconsiderar uma de suas próprias ações quando apelos eram submetidos ao Conselho de Estado. O governo não podia nem recusar a agir, nem tinha o poder discricionário de corrigir suas próprias ações. Ao invés, o governo ou tinha que seguir jurisprudência estabelecida, ou estabelecer novos precedentes, caso em que estava ampliando o corpo de jurisprudência tal como uma corte de justiça, pois uma vez que o caso fosse decidido "ficava liquidado e afirmado o direito da parte" pois de acordo com Uruguai, "o administrativo contencioso participa muito do judicial" (Souza 1960: 59).

A aplicação da doutrina de distinção e separação de poderes constitucionais aplicada à Constituição de 1824 contribuiu para criar um Executivo poderoso (Souza 1960: 32-35). O Executivo tornou-se um poder independente no sentido que controlava (exceto a aprovação de leis pelo poder Legislativo) todos os estágios do processo governamental sob a sua jurisdição, da elaboração de legislação, sua aplicação e supervisão, e a resolução de conflito. Atos administrativos, e consequentemente medidas governamentais, eram asseguradas continuidade, com todas as fases começando e terminando dentro da jurisdição deste poder. O Executivo tornou-se então o juiz de seus próprios atos. Na estrutura governamental que foi desenvolvida em 1842 e nas décadas seguintes, a prerrogativa do exercício da justiça administrativa foi de importância ímpar.

\section{Areas que Comumente Apelavam para a Seção do Império}

Os recursos submetidos à Seção do Império oferecem exemplos das várias áreas sob a jurisdição do Ministério do Império e do Ministério da Agricultura, Comércio, 
e Obras Públicas que freqüentemente entravam com recursos. Duas das mais importantes áreas sob a jurisdição do Ministério do Império eram as Presidências das Províncias e da Câmara Municipal da Cidade do Rio de Janeiro, as quais geravam em grande número problemas intrincadíssimos que após terem navegado pelas administrações municipais e provinciais finalmente apelavam para a Seção do Império. Em 1877, por exemplo, a Câmara Municipal da Cidade do Rio de Janeiro apelou contra contrato assinado pelo Ministro da Agricultura e dois engenheiros para abrir ruas no centro da cidade com o argumento de que seus direitos tinham sido violados desde que a lei que regulava os poderes das municipalidades colocava sob sua jurisdição tudo que se referisse a planejamento ${ }^{3}$.

Decisões de outros altos funcionários do governo também eram comumente apeladas. Os governos municipais, por exemplo, freqüentemente apelavam contra decisões de presidentes provinciais. Em 1879, a Assembléia Municipal da Cidade de São Paulo se reuniu para "deliberar sobre o apelo para o Conselho de Estado de decisão do Presidente Provincial" (Atas da Camara Municipal de São Paulo, Seção Ordinária, Set. 4, 1879, vol. 65, p. 112) que aceitou um apelo de dois empreiteiros cujo pedido tinha sido rejeitado pela Assembléia. Indivíduos também entravam com recurso contra atos de presidentes provinciais, como Afonso Celso de Assis Figueredo, que apelou aprovação do Presidente de Minas Gerais de uma decisão do Tesouro Provincial negando Figueredo cópia de um documento público (AN, C.555, P.4, D.51).

A área de instrução era uma das que também estava sob a jurisdição do Ministério do Império e apelava diretamente para a Seção do Império. As Faculdades de Medicina do Rio de Janeiro e Bahia, a Academia Imperial de Medicina, as Faculdades de Ciências Sociais e Jurídicas de São Paulo e Pernambuco, o Colégio Pedro II, escolas públicas primárias e secundárias e a Aula de Comércio freqüentemente apelavam em casos de litígio entre membros da faculdade e administração, e entre estudantes e administração. O professor Felipe da Mota de Azevedo, por exemplo, apelou

\footnotetext{
${ }^{3}$ Futuras referências de fontes primárias da Seção do Império obedecerão o formato AN, C.P.D. (Arquivo Nacional, Conselho de Estado, Seção do Império, Caixa 602, Pacote 2, Documento 24).
} 
a suspensão de seu salário enquanto de licença (AN, C.558, P.1, D.16) e o Reverendo Gregório Lipparoni, professor de Italiano no Colégio Pedro II, apelou a decisão que declarou vaga a sua cadeira (AN, C.562, P.2, D.16). Sob o ponto de vista jurídico, estes casos já haviam sido julgados pela administração das Escolas e os apelantes recorriam em última instância para a corte superior. Embora houvesse na cidade do Rio de Janeiro a Inspetoria Geral da Instrução Primária e Secundária da Corte, na ausência de uma autoridade administrativa intermediária entre a administração das escolas e o governo, como um Conselho Acadêmico, a Seção do Império assumiu esta função bem como a de corte de apelação.

Saúde Pública era outra área sob a jurisdição do Ministério do Império que também apelava em última instância para a Seção do Império. Esta área estava melhor organizada do que a de Instrução, pois contava com a Junta Central de Saúde Pública, a Inspeção Pública, e o Instituto Vacínico. A Junta tinha autoridade para impor penas, suspensões, ou encarceramento por infrações cometidas contra as suas regras, mas suas decisões podiam ser apeladas para a Seção do Império. Em 1886 F. Sauven \& Cia. apelou decisão da Divisão de Inspeção de Saúde contra a venda de itens estragados em sua loja (AN, C.561, P.1, D 4) e João de Deus da Cunha Pinto apelou a decisão da Divisão de fechar a Clínica Santa Teresa (AN, C.561, P.1, D.5).

Uma outra área que apelava diretamente para a Seção do Império em assuntos administrativos era a da Igreja. O Decreto 1911, de 28 de Março de 1857, regulou as regras de apelos à Coroa em matérias eclesiásticas, e com a reorganização dos Ministério em 1861, Assuntos Eclesiásticos até então sob o Ministério da Justiça, passaram à jurisdição do Ministério do Império. Na sua Divisão Eclesiástica o Ministério supervisionava a concessão, mudança, ou remoção de benefícios eclesiásticos, decidia conflitos de jurisdição e apelos à Coroa, avaliava sanção Imperial a encíclicas papais, e opinava em todos os assuntos relativos a seminários, monastérios, irmandades, e aqueles relativos à outras religiões. O Padre Francisco Gonçalves Barbosa, por exemplo, apelou da decisão de autoridades eclesiásticas negando nomeação para a posição de Cônego da Catedral de São Paulo (AN, C.562, P.1, D.11), a Irmandade de São Miguel e Almas apelou da proibição de praticar religião imposta 
pelo Vigário do Rio de Janeiro (AN, C.535, P.3, D.47). Outros apelos eram em assuntos de maior importância, como o de Joaquim Antônio de Faria Lima, que em 1871 apelou da decisão do Bispo de Olinda que recusou enterramento em campo santo ao General José Ignacio de Abreu Lima por ser este agnóstico (AN, C.551, P.4, D 66).

Apelos em assuntos eclesiásticos estavam na mesma categoria dos apelos em instrução desde que não havia um órgão intermediário entre as autoridades eclesiásticas e a alta administração do governo para regular ou disciplinar esta área como havia na área de saúde. No caso da Igreja, o governo não somente estava diretamente envolvido nos assuntos administrativos da Igreja, mas tinha que decidir em assuntos de muito maior importância do que aqueles da área de saúde ou instrução. A Divisão Eclesiástica colocava autoridades eclesiásticas sob a jurisdição do governo em todos os assuntos referentes à administração secular da Igreja, os quais incluíam apelos. Considerando esta estrutura administrativa, a tese de que durante o Império justiça administrativa contenciosa era baseada no "princípio de separação entre autoridades civis e eclesiásticas," a qual era semelhante à separação que existia entre as autoridades administrativas e judiciárias, não encontra amparo nas opiniões da Seção do Império (Aragão 1955: 48). A separação entre o Executivo e o Judiciário era baseada no princípio constitucional de divisão de poderes constitucionais. A Igreja, não era um dos poderes constitucionais, e consequentemente, não estava ao mesmo nível dos outros poderes. Em assuntos de administração secular, longe de separação entre as autoridades civis e eclesiásticas, o que em fato existia era a subordinação destas à autoridade civil. Basta mencionar que o famoso caso dos Bispos se iniciou como um assunto de administração secular, bem antes de se tornar um assunto de Estado.

A Seção do Império era também a corte de apelação nas áreas sob a jurisdição do Ministério da Agricultura as quais geravam o maior número de apelos de sociedades anônimas, companhias comerciais, contratos, concessões, construção de estradas de ferro e outras obras publicas, enfim, uma área vastíssima de litigação constante que envolvia assuntos domésticos e estrangeiros. Por exemplo, em 1875 a Dom Pedro I Railway apelou da decisão do Ministro da Agricultura que negou a concessão de juros garantidos pelo governo (AN, C. 600, P.1, D.2). Indivíduos também entravam com apelos. 
Manoel José da Costa Lima Viana apelou da decisão do Ministro da Agricultura que negou prorrogar autorização para importar trabalhadores Asiáticos (AN, C.604, P.3, D.41). O tópico do exercício de justiça administrativa, somente na Seção do Império, é vasto, pois todas as áreas sob a jurisdição dos Ministérios do Império e da Agricultura estavam incluídas. Por volta da década de 1870, a jurisprudência comercial já estava bem desenvolvida em parte devido ao surto de progresso com a construção de estradas de ferro e incorporação de sociedades anônimas (Garner 1987).

\section{Processo de Recurso}

Um aspecto importante na função das Seções do Conselho de Estado como orgãos de última instância de apelação contenciosa era a de estabelecer as áreas de jurisdição e exercício da justiça administrativa. Para justiça administrativa criar raízes e estabelecer precedentes as áreas de jurisdição do Executivo tinham que ser claramente delineadas, num processo que se desenvolveu por várias décadas e era parte do poder discricionário dos conselheiros de Estado. Na Seção do Império, todo apelo era preliminarmente examinado pelos advogados do Conselho de Estado ou pelos funcionários ministeriais para determinar se o apelo estava no caso de ser atendido e para eliminar pedidos de recurso sem mérito ou bases jurídicas (Garner 1994: 2643). Algumas das razões para negar o apelo servem para elucidar áreas do contencioso administrativo. Dos que propriamente pertenciam a área de justiça administrativa eram eliminados os que pertenciam a área de administração graciosa desde que a concessão de privilégios era uma prerrogativa graciosa do poder Executivo o qual tinha autoridade administrativa para retificar seu próprio ato caso fosse do interesse público e não envolvesse direitos adquiridos. Esta distinção entre interesse e direito adquirido não era claramente entendida por muitos apelantes. O apelo de Antônio José da Silva Travassos contra decisão do Ministro de Agricultura que negou privilégio para a navegação dos rios Possonga e Japaratuba foi recusado pela Seção do Império porque "o assunto de (concessão) privilégios não pertencia ao contencioso mas sim ao gracioso," e que se causava dano aos interesses de Travassos, não violava nenhum de seus direitos (AN, C. 591, P. 1, D. 15). 
Em seguida eram eliminados apelos que pertenciam a área do poder Judiciário e aqueles em áreas que eram, ou da jurisdição dos governos provinciais ou municipais, ou que pertenciam a áreas que davam ao governo provincial a decisão em última estância, ou eram da jurisdição de outros ministérios. O apelo de Manoel de Vasconcelos e Francisco Ferreira Borges contra decisão do Presidente de Sergipe ordenando que fosse paga ao Tesouro uma multa, foi recusado pela Seção do Império por ser "matéria de interesse puramente provincial... sobre a qual o governo Imperial não tinha jurisdição para resolver" (AN, C.556, P.2, D.28). Apelos em casos de justiça civil ou criminal também eram recusados baseados na separação entre o Judiciário e o Executivo. Um apelo relacionado à indenização de terreno desapropriado para a construção da Pernambuco Railway foi recusado pela Seção do Império por ser um caso de lei civil que deveria ser decidido pelo Judiciário (AN, C.602, P.1, D.4). A Seção tão pouco aceitava apelos de casos de litígio entre indivíduos, ou entre indivíduos e a administração de companhias comerciais, os quais eram sempre negados porque o "Poder Executivo é incompetente para conhecer tais questões" (AN, C.596, P.3, D.59).

Finalmente, eram eliminados os apelos que davam entrada fora do prazo de dez dias prescrito por lei. Por exemplo, o Marquês de Olinda recusou o apelo de Jacob Humbird contra ato do Ministro de Agricultura que negou pagamento de juros numa quantia devida à ele pelo governo porque "estava além do limite de prazo de dez dias e não podia ser considerado" (AN, C.591, P.2., D.38). Em apelos iniciados nas províncias dois fatores eram considerados: o das distâncias, e o de não haver contencioso administrativo provincial. Ainda assim as disposições do Regulamento 124 eram observadas e o apelo era interposto para o Presidente da Província, o qual remetia o pedido acompanhado de todos os documentos necessários para a respectiva Secretaria de Estado. Na prática, entretanto, havia certas realidades que não podiam ser olvidadas. A formalidade do prazo era obedecida o tanto quanto possível, mas devido as distâncias não era fator suficiente para rejeição se o apelo envolvesse assunto de alta importância política para o Estado, em cujo caso os conselheiros de Estado tinham o poder discricionário de aceitar o apelo. Esta combinação de fatores 
levou o Visconde de Bom Retiro à aceitar o apelo da Irmandade do Santíssimo Sacramento, de Recife, aos 28 de Maio de 1873 embora a data de impetração estivesse dez dias além do prazo. Ao aceitar o apelo Bom Retiro considerou a situação política, reconheceu que o apelo da Irmandade era de suma importância para ser recusado, e relevou uma das regras essenciais para aceitação de apelos, a do prazo de dez dias (AN, C.551, P.4, D.68). Este ato de triagem preliminar eliminava não somente os casos não contenciosos mas ainda, como asseverou o Marquês de São Vicente, tinha o fim de "impedir que homens obscuros agitem pretensões injustas" (Bueno 1857: 28-31).

Dos apelos que eram propriamente litigiosos, uma outra distinção era necessária, a de ações administrativas do Executivo no exercício de suas funções constitucionais. Em muitos casos, não era fácil distinguir entre os poderes administrativos e constitucionais do Executivo, causando muitos apelos que questionavam o que aparentemente eram decisões administrativas mas que em realidade eram decisões constitucionais que davam ao Executivo o poder de puro mando. Nestes casos, o único meio de remediar a situação era através de petições, um processo fora da área litigiosa. O apelo de Henrique Leal e Francisco Arthur Bowen, representantes da Reed Bowen Cia, Londres, contestou decisão do Executivo que em 1882 declarou que a Estrada de Ferro de Recife à Limoeiro e extensão a Nazareth, até então uma estrada provincial de Pernambuco, passava a ser estrada de interesse nacional em conseqüência de sua conexão com a Conde d'Eu Railway na Província da Paraíba. Os reclamantes em realidade tinham direitos adquiridos no contrato que tinham com o governo de Pernambuco para construir o trecho de Nazareth à Timbauba, mas o governo geral ao declarar a estrada de interesse nacional, contratou com a Brazil Great Western Railway Cia. para a construção do trecho. Ao negar o apelo, os conselheiros decidiram que "o governo agiu dentro da plenitude de seus direitos quando decidiu em assunto de interesse geral, do qual é o juiz supremo" (AN, C.606, P.2, D.28).

As razões pelas quais os conselheiros rejeitavam apelos eram várias, mas em cada caso havia sempre o procedimento de separar e diferenciar entre áreas de jurisdição dos poderes em questão, entre o Executivo e o Judiciário, entre o governo central e provincial, entre jurisdição administrativa, civil, e criminal, e entre adminis- 
tração graciosa e contenciosa. Cada rejeição ou aceitação era um precedente para a jurisprudência administrativa. Em uma opinião emitida em 1881, os conselheiros da Seção do Império enunciaram este processo com clareza absoluta: em referência a companhias comerciais, disseram eles, a Seção tem "procurado discriminar as raias da jurisdição administrativa...de modo a concorrer por sua parte para que se mantenha sempre ilesa a órbita da ação do Poder Judiciário" (AN, C.605, P.1, D.7).

Esta fase era importantíssima para a implantação da justiça administrativa, pois disciplinava o prazo para aceitação de recursos, firmava a área de jurisdição de administração contenciosa e a diferenciava da graciosa, e, ao definir a área de jurisdição do contencioso implicitamente definia a área do poder Judiciário. Esta triagem se fazia ainda mais necessária pelo fato de que a medida que o Conselho de Estado se institucionalizou como tribunal de apelação de justiça administrativa, o público adquiriu o hábito de apelar ao Conselho de Estado ao invés do Judiciário, mesmo em casos que estavam sob a jurisdição deste último poder. Os comentários do Marquês de São Vicente indicam a prioridade deste escrutínio: "Nenhum dêles (advogados) deve apresentar como contenciosos negócios que não tenham esse carácter, nem recorrer ao Conselho sobre assuntos que sejam da competência de outra autoridade" (Bueno 1857: 290).

\section{As Fases do Processo}

No início do processo, a parte apelante dava entrada na respectiva Diretoria do Ministério do Império ou da Agricultura com a petição de recurso acompanhada dos documentos substanciando o pedido, o qual era examinado por um dos advogados do Conselho para determinar a validade da petição, e a notícia do apelo era publicada por três dias consecutivos no jornal de grande circulação, geralmente o Diário Oficial (Regulamento 124, Arts. 33, 39).

Uma vez aceito o apelo, o advogado assinava o pedido de recurso. Na fase inicial do recurso o advogado era ainda permitido assinar "quaisquer alegações ou arrazoados que tiverem que ser apresentados ao Conselho e as suas Seções" bem como assistir ao depoimento e mais atos do Art. 35, pelo qual as Seções podiam requerer 
das partes avaliações, interrogação de testemunhas, depoimentos das partes, ou qualquer outra medida julgada necessária para julgar o recurso. Uma destas medidas era o preparo da "Razão do Recurso". A "Razão" era um dos documentos enviados ao conselheiro da Seção do Império designado relator para o julgamento do recurso . O preparo deste documento não está claramente enunciado entre as funções do advogado do Conselho, mas pode ser aceito como uma interpretação do Art. 37 do Regulamento 124, o qual permite ao advogado assinar as "petições e quaisquer alegações ou arrazoados que tiverem de ser apresentados ao Conselho e as suas Seções”. Um exemplo deste tipo de documento está transcrito na opinião emitida pela Seção do Império sobre o recurso interposto por Feliciano Joaquim de Bormam relativo ao prejuízo que disse ter sofrido como concessionário da Estrada de Ferro de Pôrto Alegre a Uruguayana, na Província do Rio Grande do Sul.

Nesta opinião, os conselheiros da Seção do Império, Visconde de Jaguary (relator), Visconde do Bom Retiro, e José Pedro Dias de Carvalho transcrevem, entre outros documentos anexos ao processo, a "Razão do Recurso" preparada pelo advogado do Conselho de Estado Joaquim Saldanha Marinho em 2 de Outubro de 1877. Este documento é importante porque revela como as "razões" eram articuladas.

O documento identifica em ordem de precedente: nome do recorrente, cidade e província de residência. Ato recorrido: indeferimento pelo Ministro de Agricultura, Comércio, e Obras Públicas de petição que pedia indenização do valor das perdas e danos de trabalhos de exploração para a construção da ferrovia de acordo com o convencionado por contrato autorizado por lei provincial. Exposição da defesa: Saldanha Marinho argumenta que o ato do Ministro destruiu direito adquirido, daí causando dano e esbulho ao recorrente, expõe os fatos "taes e quaes se passaram" mantendo que atos do Governo Provincial referentes à viação pública, incluindo estradas de ferro dentro de províncias, e de competência das autoridades provinciais, não podiam ser invalidados pelo Governo Imperial. Cita os termos do contrato entre

\footnotetext{
${ }^{4} \mathrm{O}$ relator era selecionado pelo Ministro dentre os três membros da Seção do Império.
} 
Bormam e o governo provincial, termos que a seu ver foram ignorados pelo Governo Geral quando autorizou estudos para uma linha férrea entre Pôrto Alegre e Uruguayana, a qual invadia a zona de privilégio de Bormam. Tal ato, que prejudicou o esforço do recorrente de organizar a companhia para construção da estrada de ferro, rendeu os estudos preliminares para a construção da estrada inúteis, causando prejuízo considerável ao recorrente, que então apresentou reclamação ao Governo Geral, o qual declarou que tomaria na devida consideração a reclamação. Tendo o traçado escolhido pelo Governo Geral infringido nos direitos adquiridos pelo recorrente, o Governo Geral mandou avaliar os prejuízos causados ao recorrente, mas a comissão encarregada da avaliação nunca concedeu audiência à Borman para decidir a apreciação do valor da indenização. Saldanha Marinho argumenta em favor de justa avaliação e contra o ato do Ministro da Agricultura que indeferiu a petição quando já havia o precedente de semelhante e razoável compensação concedida a outro recorrente de outra estrada de ferro (AN, C.602, P.1, D.11).

Quão importante era a "Razão do Recurso" preparada pelo advogado do Conselho de Estado para a decisão do conselheiro relator? Na prática, a "Razão do Recurso" era apenas um dos muitos documentos que formavam os processos de recurso a serem avaliados pelos conselheiros. Nos seus pareceres estes eram assessorados em todas as áreas por um grande número de opiniões emitidas por autoridades e especialistas. Ministros e presidentes de província eram chamados a prestarem esclarecimentos, o Procurador Geral da Coroa emitia pareceres, bem como qualquer outra autoridade necessária. Um exemplo é o recurso interposto por Miguel Calógeras que requereu pareceres da Diretoria das Obras Públicas da Província do Rio de Janeiro, seguido da informação prestada pelo Chefe Interino da Diretoria das Obras Públicas do Ministério da Agricultura, seguido pelo parecer do Chefe efetivo da dita Diretoria (AN, C. 604, P. 1, D. 16). Na maioria dos casos, os próprios funcionários dos Ministério do Império ou da Agricultura apresentavam longos resumos dos casos, citavam precedentes, e opinavam se os pedidos de recurso estavam no caso de serem aceitos ou indeferidos, muitas vezes contrariando a opinião do advogado do Conselho. No recurso de Bormam os fundamentos da decisão do Mi- 
nistro que estava sendo recorrida tinham sido apresentados num parecer de Buarque de Macedo, funcionário da Diretoria das Obras Públicas do Ministério da Agricultura que opinou por indeferimento, enquanto que Saldanha Marinho, categoricamente pediu deferimento do recurso. Este recurso contribui para uma visão mais precisa da função ao mostrar o funcionário do Ministério da Agricultura expondo o caso do Governo, o advogado do Conselho de Estado advogando o caso do recorrente, e demonstrando que a decisão final quanto a validade do recurso não era decidida nesta fase inicial pelo advogado. Passada esta fase o processo de apelação seguia um curso determinado. Esta “Razão do Recurso" preparada pelo advogado do Conselho não deve ser confundida com as razões de recurso que eram preparadas pelos advogados dos apelantes, as quais geralmente eram elaboradas e até imprimidas em tipografias e apresentadas ao Conselho com todos os documentos do apelo, como as Razões de Recurso da Estrada de Ferro do Cahy (AN, C.606, P.2, D.26).

O recurso interposto por Ana Joaquina do Pinho Souto em 1875 serve para ilustrar este curso. O recurso foi interposto contra ato do Ministro da Agricultura que ratificou decisão do Presidente da Província do Rio de Janeiro autorizando melhoramentos na estrada que cruzava a propriedade de Ana Joaquina. Em 10 de Fevereiro de 1875, Saldanha Marinho como advogado do Conselho de Estado deu entrada no Ministério da Agricultura com a petição inicial de recurso pedindo que o caso fosse examinado e que a apelante fosse informada de seus direitos. O recurso foi enviado à Seção do Império e em 2 de Abril o Visconde do Bom Retiro foi designado relator. Em 5 de Abril ele requisitou do Ministério da Agricultura toda informação pertinente ao caso, bem como a exposição do advogado do Conselho demonstrando as razões para o recurso, e aos 13 do mesmo mês ambas as partes, Ana Joaquina e o Ministro da Agricultura, foram permitidas examinar os documentos (AN, C.600, P.1, D.12-A). Após terem sido preenchidas todas as formalidades, e em posse de toda a documentação do processo e das exposições de ambas as partes, o conselheiro relator emitia sua decisão.

Na década de 1880, um apelo típico dos que eram constantemente submetidos à Seção do Império foi o da Southern Brazilian Rio Grande do Sul Railway. Em 8 de Julho de 1886 o Chefe da Divisão de Obras Públicas do Ministério da Agricultura 
recebeu o apelo da Estrada de Ferro com todos os documentos pertinentes. A notícia do apelo foi publicada três dias consecutivos no Diário Oficial, 10, 11, e 12 de Julho. Em 12 de Julho, o representante da Estrada de Ferro compareceu perante a Divisão de Obras Públicas e deu depoimento mostrando causa para o apelo, declarando que a Estrada de Ferro estava apelando de decisão do Ministro que declarou sem efeito a concessão para a construção da estrada de Ferro de Bagé a Cacequí. Em 25 de Julho o apelo foi enviado ao conselheiro relator, o Visconde de Sinimbu, que determinou em 30 de Julho que as partes fossem dadas vista dos documentos. A sua decisão foi anunciada em 1 de Agosto no Diário Oficial. Em 2 de Agosto, o representante da Estrada de Ferro recebeu do Ministério os documentos para exame e os devolveu aos 12 de Agosto, apresentado o argumento em suporte do apelo. Em 21 de Agosto todos os documentos foram enviados ao Visconde de Sinimbu para a decisão final. A Seção do Império anunciou a decisão em 1 de Setembro de 1886 (AN, C.608, P.3, D.12).

\section{Desvio de Poder}

A institucionalização da justiça administrativa no Brasil em 1842 também ilumina vários aspectos do sistema de governo e seu funcionamento durante o Segundo Reinado. Um se refere a posição do Conselho de Estado em relação ao Gabinete. Oficialmente, os conselheiros de Estado nas Seções eram subordinados aos ministros, a quem aconselhavam em decisões administrativas, preparo de legislação, e outros assuntos. Mas ao exercerem a função de corte de apelação de justiça administrativa, os conselheiros estavam acima dos ministros, pois em muitos dos casos eles julgavam as decisões destes e podiam anular ato do ministro. A opinião emitida pela Seção do Império no recurso de Carlos Jacob Schilling contra o Ministro da Agricultura na expiração do prazo para a construção da Estrada de Ferro do Cahy foi crítica da decisão do Ministro, a qual foi considerada "sumamente severa," e várias decisões similares anularam atos ministeriais (AN, C.606, P.2, D.26).

Um outro aspecto é que, esta função de corte de apelação de justiça administrativa das Seções do Conselho de Estado permitia um supervisionamento dos ministros no que se refere ao abuso de poder, no caso de uma autoridade administrativa 
tomar uma decisão "ou praticar um ato excedente das atribuições marcadas pela Lei" (Souza 1960: 68). Este conceito, elaborado pelo Conselho de Estado francês em 1864, já estava contido no Regulamento 124 ao permitir apelos para o Conselho de Estado de decisões de ministros e presidentes provinciais, e eventualmente, a medida que a justiça administrativa foi sendo institucionalizada, serviu também para supervisionar outros altos funcionário da administração, como os da Junta de Saúde, etc. Esta função de agir em casos de abuso de poder era usada com cuidado, mas quando usada, era extremamente efetiva. A decisão da Seção do Império num recurso da Companhia Ferro-Carril Vila Izabel de uma multa imposta pelo Ministro da Agricultura, concluiu com a recomendação de que a multa fosse anulada e que o decreto do Ministro fosse "considerado sem efeito" (AN, C.607, P.3, D.17). O caso de arbitramento da Leopoldina Railway é um exemplo ainda mais poderoso para ilustrar este poder. Quando o Ministro da Agricultura tomou a sí resolver a disputa agindo como árbitro e como Ministro, e a decisão foi apelada para a Seção do Império, a decisão foi fulminante, embora elaborada numa linguagem delicada e cortês. $\mathrm{O}$ Ministro, decidiram os conselheiros, "atento ao juízo claro e refletido de que é dotado" não podia absolutamente ter pretendido agir como árbitro desde que o contrato estipulava que no caso de falta de acordo entre os árbitros, as disputas eram resolvidas pela Seção do Império do Conselho de Estado. Consequentemente, as ações do Ministro não eram mais do que "simples decisões ministeriais, e como tal, podiam ser explicadas, alteradas, substituídas, ou repelidas a qualquer momento..." (AN, C.604, P.1, D.6 ). As decisões das Seções do Conselho de Estado em assuntos de justiça administrativa eram finais. Teoricamente havia apelo para $\mathrm{o}$ Imperador, mas nos casos de justiça administrativa Pedro II nunca interferia, e as decisões da Seção do Império tinham o efeito de lei uma vez assinadas pelo chefe do poder Executivo.

\section{Expansão}

A expansão da justiça administrativa e contenciosa se fez através de vários modos, pois o Regulamento 124 foi apenas o início. O modo desta expansão estava 
ligado ao sistema administrativo que começou a ser implementado em 1842, e às funções do Conselho de Estado. Uma das formas desta expansão era constitucional, que dava ao Executivo a prerrogativa de emitir os regulamentos para leis aprovadas pelo Legislativo. A outra, se prendia às funções do Conselho de Estado, que além de preparar e revisar os projetos de lei apresentados ao Legislativo, também preparava ou revisava projetos de regulamento uma vez que a lei tivesse sido aprovada. E era nos regulamentos, e não na lei, que ficava especificado a forma de apelo e órgão de apelação em assuntos contenciosos em primeira e última instância, quando então eram nomeadas as Seções do Conselho de Estado como órgãos de apelação de última instância, ou, como o único órgão de apelação. Por exemplo, o projeto para a criação da Divisão Central de Saúde Pública preparado pela Imperial Academia de Medicina, foi enviado à Seção do Império para revisão em Outubro de 1849, tornou-se lei em 1850, e foi dado regulamento em 1851. A forma de apelação das decisões da Divisão estava contida no artigo 29 do regulamento, não na letra da lei (AN, Conselho de Estado, Seção do Império, Códice 50, vol. 2, Out. 22, 1849). Assim, cada vez que o Executivo preparava ou revisava um regulamento, mais se institucionalizava a justiça administrativa contenciosa.

Similarmente, em contratos assinados entre o governo e particulares, e nos estatutos das companhias comerciais sob a jurisdição dos Ministério do Império e da Agricultura que tinham que ser submetidos ao governo para revisão, cláusulas eram inseridas nomeando a Seção do Império a corte de apelação em qualquer disputa entre o governo e as companhias. Quando o Barão de Mauá recebeu permissão para transferir suas companhias no Brasil para interesses britânicos em 1862, a Seção do Império deu opinião favorável mas com a condição de que ficasse bem entendido que no contrato para a Rio de Janeiro Gás Company, "o Conselho de Estado é a segunda e última instância para apelos entre o governo e indivíduos por um lado, e companhias por outro" e, além do mais, "que as palavras = Conselho de Estado = queren dizer a Seção do Conselho de Estado" (AN, C.588, P.3, D.61).

Uma das críticas de Tavares Bastos à institucionalização da justiça administrativa no Brasil era de que o Regulamento 124 era vago (Bastos Carta II: 14). Todavia, 
deve ser levado em consideração que em 1842, quando a justiça administrativa foi institucionalizada, não era possível já estabelecer em detalhe todas as formas de apelo, simplesmente porque o corpo de jurisprudência ainda estava por ser desenvolvido e a administração não estava ainda suficientemente organizada. Nos Ministérios do Império e da Agricultura, jurisprudência administrativa foi estabelecida e desenvolvida ao longo com o desenvolvimento da administração, num processo que era o produto de experiência, não de teoria. Assim, quanto maior o número das áreas organizadas, mais justiça administrativa se institucionalizava, e mais as Seções do Conselho se tornavam cortes de apelação em última instância. Não havia limite à esta expansão. O Executivo estava estrategicamente situado para esta função, pois controlava o processo de confecção de projetos de leis desde a fase inicial, controlava a confecção dos regulamentos, e ultimamente, a resolução de conflitos. Esta continuidade deu a necessária estabilidade administrativa requerida para estabelecer o corpo de precedentes. Em 1875, este fato foi mencionado numa opinião da Seção do Império, que relembrou a necessidade de reinforçar regulamentos "a fim de formar um corpo de jurisprudência" (AN, C.599, P.3, D.83). Era um processo no qual nem o Legislativo e nem o Judiciário estavam envolvidos.

\section{Conclusão}

A análise da institucionalização da justiça administrativa no Brasil durante o Reinado de Pedro II serve para elucidar várias áreas da historia nacional. Uma, é como a área da justiça administrativa foi estabelecida e expandida e o modo de sua introdução, que foi através de um Regulamento provisório e não na letra da Lei que reinstituiu o Conselho de Estado, dando à entender a muitos estudiosos que a justiça administrativa nunca realmente teve exercício no Brasil. A outra é que a análise das fontes da Seção do Império oferece prova contundente de que tal não era o caso. Não somente o Conselho de Estado nas suas Seções teve atribuições jurisdicionais, como também a jurisdição administrativa teve organização metódica e regular. $\mathrm{O}$ formato no Conselho de Estado, todavia, era diferente daquele do poder Judicial, e mais próximo daquele do Conseil d'État francês. O volume de opiniões das Seções 
do Conselho de Estado é imenso, e as áreas muitíssimas, tanto as pertinentes ao administrativo gracioso e ao contencioso como aquelas relacionadas com outras áreas, e levará décadas para que a história e as funções da instituição menos conhecida na história nacional sejam devidamente dadas a luz

Ainda de grande relevância é determinar a influência herdada do Conselho de Estado nas instituições modernas. Embora a Lei 234 desse ao Conselho de Estado somente uma função consultiva, a função judicial criada no Regulamento 123 foi exercida de 1842-1889, e a jurisprudência administrativa criada pela Seção do Império passou a ser reconhecida como lei. Com a passagem dos anos, a acumulação de decisões começou a formar o corpo de precedentes e estes eram citados como qualquer outras decisões judiciais. Os apelantes citavam estes precedentes no histórico de seus apelos tanto quanto os conselheiros ao emitirem suas decisões. $\mathrm{O}$ apelo de Benjamim Salvado e Cia. contra ato do Presidente de São Paulo em 1880, foi baseado em cinco decisões da Seção do Império, a primeira datada de 1843 (AESP, T-1, Vindos, Avisos do Ministério do Império, Ordem 7713, Caixa 9, Livro 34, Ano 1880, 9 de Fev.). O Legislativo eventualmente também reconheceu a função do Conselho de Estado como corte de apelação em matérias contenciosas. A longa disputa entre a Câmara Municipal de São Paulo e a Companhia Ingleza para a abertura da Rua Helvétia foi dada por finda quando um dos membros daquela Câmara declarou que a Companhia Ingleza "tinha perdido todos os apelos para o governo provincial, o governo central, e o Conselho de Estado" (Atas da Câmara Municipal da Cidade de São Paulo, Seção Extraordinária, vol. 70, 24 de Abril, 1884: 91-93).

O Judiciário eventualmente também reconheceu a distinção entre os seus poderes e os da administração através do reconhecimento do Conselho de Estado como corte de justiça administrativa. Este poder consistentemente decidia que não tinha jurisdição sobre companhias comerciais, associações ou investidores quando o apelo envolvesse assunto específico de contratos. Em 1887, a Corte de Apelação do Rio de Janeiro reconhecia o sistema duo de justiça ao decidir num apelo contra a Cia. Carris Urbanos que "o Judiciário não tinha jurisdição para decidir em matéria de direitos cuja fonte é puramente administrativa" (O Direito, Apelação Civil n. 5918, 
vol. 44, Set./Dez. 1887: 550). Apesar da institucionalização da justiça administrativa, esta foi aceita com entusiasmo por muitos, e com reservas por outros que liam na Constituição um sistema unitário de justiça, uma ambivalência que permaneceu até o fim da monarquia e que era perfeitamente ilustrada na revista O Direito. Nas décadas de 1870 e 1880 a revista publicava doutrinas de justiça administrativas, casos de contencioso administrativo provincial, nas seções de Legislação e Conselho de Estado publicava as resoluções de consultas das Seções do Conselho de Estado, e opiniões sobre o valor de um parecer do Conselho de Estado perante a lei internacional (O Direito, vol. 7, Maio/Agosto 1875: 259-288; vol. 10, Maio/Agosto 1876: 892-901; vol. 12, Jan/Abril 1877: 828-880; vol. 18, Jan/Abril 1879: 15-24).

A análise do exercício da justiça administrativa pelas Seções do Conselho de Estado é também relevante para o período republicano, pois introduz a questão de como o Judiciário manejou a herança do corpo de jurisprudência administrativa legada pelo Império, desde que a eliminação de todos os precedentes estabelecidos é uma tese que não poder ser aceita. Daí a importância da tese de Manuel Pedro Vilaboim, quem primeiro levantou a questão em 1892, se perante a Constituição de 1891 o contencioso administrativo havia sido abolido ou continuava a existir (Vilaboim 1892). E como no caso da Constituição de 1824, para alguns dependia da interpretação dada àquela Carta (Masagão 1927). A prática da justiça administrativa é historicamente tão arraigada, que é bem possível que o contencioso administrativo continue de uma forma que não é claramente reconhecida como tal. José Cretella Junior, no seu Tratado de Direito Administrativo aventa a suspeita:

Cabe indagar, nesta altura, se não restou a menor dúvida quanto a abolição total, para sempre, do contencioso administrativo, no Brasil. Não existe setor algum da administração que não profira decisões juridicionais? ... Não será o Tribunal de Contas um órgão judiciário? Qual o valor de suas decisões? Quem julga contas exerce funções judicantes? (Cretella Junior 1969: 102)

Finalmente, um conhecimento mais profundo da instituição do Conselho de Estado do Segundo Reinado e do Contencioso Administrativo contribui para colocar 
a nossa história nacional no âmbito mais abrangente da história Latino-Americana e das Américas. A herança cultural i•Ibérica de governos conciliares e a influência do modelo francês do Conseil d'État influenciaram não somente o Brasil, como também o México, a Guatemala, a Bolívia e outros países que tiveram seus Conselhos de Estado e exerceram justiça administrativa. O Conselho de Estado brasileiro do Segundo Reinado provavelmente foi o mais bem organizado e eficaz, mas no momento um estudo comparado deste com outros Conselhos dos Estados Latino Americanos não é viável dada a ausência de estudos, indicação de fontes, e até mesmo menção nas histórias destes países ${ }^{5}$.

\section{Apêndice}

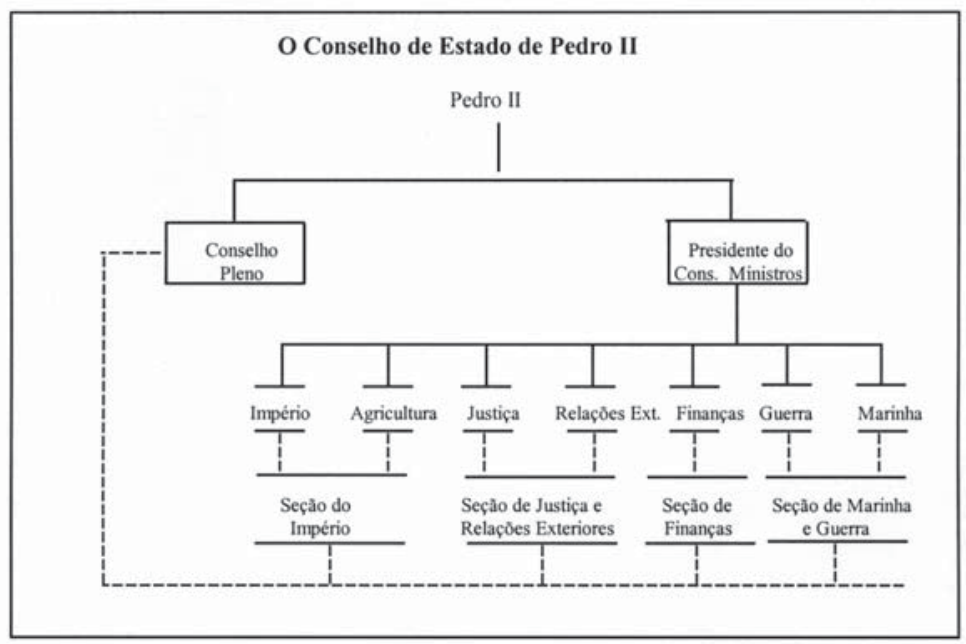

Fonte: Lydia M. Garner, "In Pursuit of Order: A Study in Brazilian Centralization, The Section of Empire of the Council of State 1842-1889.” Tese de Doutoramento, The Johns Hopkins University, 1987.

\footnotetext{
${ }^{5}$ A obra de Teodosio Lares, Lecciones de Derecho Administrativo, publicada em 1851 serve como introdução ao estudo do direito administrativo no México.
} 


\section{Ministério do Império em 1862}

Presidência das Províncias, Hospital do Lazareto de Jururuba, Tribunal da Junta de Comércio, Arquivo Público do Império, Hospital Marítimo de Santa Isabel, Escolas Públicas de Primeiras Letras, Museu Nacional, Instituto Vacínico do Império, Aula de Comércio da Corte, Hospital dos Lázaros, Comissão das Obras Públicas a bem da Sanidade, Academia Imperial de Belas Artes, Faculdades de Medicina, Montepio Geral de Economia dos Servidores do Estado, Biblioteca Nacional e Pública da Corte, Academia Imperial de Medicina, Diretoria do Senso Geral do Império, Imperial Colégio de Pedro II, Academia de Ciências Jurídica s e Sociais de São Paulo e Pernambuco, Comissão de Engenharia, Instituto Histórico e Geográfico Brasileiro, Junta Central da Higiene Pública, Inspetoria Geral dos Teatros Subvencionados, Repartição de Estatística do Império, etc...

A Divisão Eclesiástica; A apresentação, permuta e remoção dos benefícios eclesiásticos, dispensas e atos respectivos; Os conflitos de Jurisdição e os recursos à Coroa, em matéria eclesiástica; O beneplácido imperial e licenças prévias para as graças espirituais que se impetram da Santa Sé e seus delegados; Os negócios com a Santa Sé e seus delegados; Os negócios relativos aos seminários, conventos, Capela Imperial, ordens terceiras, irmandades e confrarias; Os negócios relativos aos outros cultos acatólicos; O Montepio Geral dos Servidores do Estado.

\section{Ministério da Agricultura, Comércio e Obras Publicas (Criado em 1860)}

Negócios relativos ao comércio, Desenvolvimento da indústria e ensino profissional, Estabelecimentos industriais e agrícolas, Melhoramentos de raças de animais e escolas veterinárias, Coleção e exposição de produtos industriais e agrícolas, aquisição de Plantas e sementes, Jardim Botânico e Passeio Público, Sociedade Auxiliadora da Indústria Nacional, Institutos agrícolas, Mineração (excetuados os terrenos diamantinos), Autorização para incorporação e de estatutos de companhias comerciais, Concessão de patentes, e de prêmios, Todos os negócios concernentes à questão de terras, Colonização (exectuadas as colônias militares), Catequese dos Índios e missões indígenas, Obras públicas na Corte e nas províncias feitas pelo 
Estado, Estradas de Ferro e de Rodagem, Navegação Fluvial e os paquetes, Correios terrestres e marítimos, Iluminação pública da Corte, Serviços de extinção de incêndios e companhias de bombeiros. Em 1862 as seguintes Repartições foram transferidas do Ministério do Império para o da Agricultura

Diretoria Central e dos Negócios da Agricultura, Comércio e Indústria; Diretoria das Obras Públicas e Navegação; Diretoria das Terras Públicas e Colonização; Diretoria Geral dos Correios; Administração do Correio Geral da Corte e da província do Rio de Janeiro; Inspetoria Geral das Obras Públicas; Administração dos Telégrafos Aéreos da Corte; Telegrafo Elétrico; Companhia Brasileira dos Paquetes à Vapor; Sociedade Auxiliadora da Indústria Nacional; Imperial Instituto Fluminense de Agricultura; Jardim Botânico; Passeio Público; Companhia de Estrada de Ferro D. Pedro II; Corpo de Bombeiros; Agencia Oficial de Colonização; Montepio Geral dos Servidores do Estado.

Fonte: Max Fleiuss, Hitória Admi nistrativa do Brasil 2nd. ed. (São Paulo: Companhia Editora Melhoramentos, 1922), pp. 192-206; 236-239.

\section{Referências Bibliográficas}

Arquivos e Fontes Primárias

Arquivo do Museu Imperial. (AMI). Petrópolis.

Arquivo Estadual do Estado de São Paulo (AESP).

Arquivo Nacional. (AN). Rio de Janeiro.

Atas da Câmara Municipal de São Paulo. 1879.

Atas da Câmara Municipal da Cidade de São Paulo. 1884.

Jornais e Revistas

O Direito. 1887.

Revista do Instituto da Ordem dos Advogados Brasileiros.1865. 1881. 1882.

A Província de São Paulo. 1875.

O Diário de São Paulo. 1875. 
ALMEIDA, Fernando H. Mendes de Almeida. Constituições do Brasil. São Paulo, Edição Saraiva, 1954.

ARAGÃO, J. Guilherme de. La Juridiction Administrative au Bresil. Tese de Doutoramento em Direito, Faculdade de Direito de Paris, 1955.

BARROS, Henrique do Rego. Apontamentos sobre o Contencioso Administrativo e sobre os Privilégios e Prerrogativas nos Contratos e Transações que celebra com o Público. Rio de Janeiro, Editora Laemmert, 1874.

BASTOS, A.C. Tavares. Cartas ao Solitário. São Paulo, Companhia Editora Nacional, 1975.

BUENO, José Antonio Pimenta. Marquês de São Vicente. Direito Público Brazileiro e Analyse da Constituição do Império. Rio de Janeiro, Tipografia de J. Villeneuve e Co., 1857.

CABRAL, P.G.T. Veiga Cabral. Direito Administrativo Brasileiro. Rio de Janeiro, Typ. Laemmert, 1859.

CAVALCANTI, Temístocles Brandão. Tratado de Direito Administrativo, Vol. IV, $5^{\text {th }}$ ed., Rio de Janeiro: Livraria Freitas Bastos S.A., 1964.

CRETELLA JUNIOR, José. "O Contencioso Administrativo na Constituição Brasileira." Revista de Direito Público, vol. 19, Ano V, Jan/Mar 1972, pp. 37-50; Tratado de Direito Administrativo. Vol. VI. São Paulo, Publicações Forenses, 1969.

DALLARI, Dalmo de Abreu. "O Conselho de Estado e o Contencioso Administrativo no Brasil.” Revista de Direito Público, vol. 11, Ano III, Jan/Mar 1970, pp. 33- 44.

FLEIUSS, Max. Historia Administrativa do Brasil. 2nd. ed. São Paulo, Companhia Melhoramentos de São Paulo, 1922. pp. 221-222.

GARNER, Lydia Magalhães Nunes. "In Pursuit of Order: A Study in Brazilian Centralization, The Section of Empire of the Council of State, 1842-1889". Tese de Doutoramento, The Johns Hopkins University, 1987, 2 Vols.;

"The Transatlantic Influence in the Reinstatement of the Council of State," Chp. II, em The Council of State of the Brazilian Monarchy, 1842-1889: The Organization of a New American State (em processo de revisão, 2002);

"Os Advogados do Conselho de Estado do Segundo Reinado, 1842-1880," em Revista do Instituto dos Advogados Brasileiros, n. 81, 1. e 2. Semestres, 1994, pp. 27-43.

LARES, Teodosio. Lecciones de Derecho Administrativo. 2nd. edição. México, Universidad Nacional Autónoma de México, 1978.

LYRA, Augusto Tavares de. Instituições Politicas do Império. Brasília, Editora da Universidade de Brasília, 1979. 
MASAGÃO, Mário. "Em face da Constituição Federal, não existe, no Brasil, o contencioso administrativo." Tese. 1927.

ROCHA, Alfredo “O Contencioso Administrativo: Teve ele uma Organização Regular?”, Revista do Instituto Histórico e Geográfico Brasileiro, Primeiro Congresso de Historia, 1914, vol. 3.

SOUZA, Paulino José Soares de. Visconde de Uruguai, Ensaio sobre o Direito Administrativo. Rio de Janeiro: Serviço de Documentação do Ministério da Justiça e Negócios Interiores: Departamento de Imprensa Nacional, 1960.

TÁCITO, Caio.’Teoria e Prática do Desvio de Poder'. Revista de Direito Administrativo, vol. 117, Jun/Set, 1974, p. 1-18; “Contencioso Administrativo,” RDA. 133, Jul/Set 1978, pp. 59- 69.

VIDAL, Roger. “A Evolução do Desvio de Poder na Jurisprudência Administrativa.” $\underline{R D A}$, vol. 30, pp. 34-65.

VILABOIM, Manuel Pedro. "Qual o caráter do contencioso administrativo perante a Constituição Federal?” em Revista da Faculdade de Direito de São Paulo. 1893. 